\title{
The normal range of mouth opening in a group of Albanian population
}

\author{
Silvana Beraj ${ }^{1}$, Gentian Vyshka ${ }^{2}$ \\ ${ }^{1}$ Orkidea Clinic, Tirana, Albania; ${ }^{2}$ Faculty of Medicine, University of Medicine in Tirana, Tirana, Albania \\ Contributions: (I) Conception and design: S Beraj; (II) Administrative support: S Beraj; (III) Provision of study materials or patients: S Beraj; (IV) \\ Collection and assembly of data: S Beraj; (V) Data analysis and interpretation: All authors; (VI) Manuscript writing: All authors; (VII) Final approval \\ of manuscript: All authors. \\ Correspondence to: Gentian Vyshka. Faculty of Medicine, University of Medicine in Tirana, Tirana, Albania. Email: gvyshka@gmail.com.
}

\begin{abstract}
Background: Temporomandibular disorders involve a pool of musculoskeletal disorders expressed by pathological changes in anatomical level of temporomandibular joints (TMJs) and/or abnormal activity of masticatory muscles which will directly affect the functionality of this system and will be expressed clinically as: facial pain, jaw joint pain, headaches, earaches, dizziness, masticatory musculature hypertrophy, limited mouth opening, occlusal disease, clicking sounds in TMJs.

Methods: The patterns of mandibular movements (range and direction) are widely studied to assess dysfunction of the masticatory system. We measured the maximal mouth opening (MMO) in the maximal mouth opening position through a Vernier calipers, with a $0.05 \mathrm{~mm}$ accuracy to measure the maximal mouth opening. The study group enrolled 1,348 adults, aged 20-78 years old.

Results: The average maximum mouth opening for all participants was $43.1 \pm 2.49 \mathrm{~mm}$, and the mean MMO of males was $43.6 \pm 3.63 \mathrm{~mm}$, and in females $40.8 \pm 1.38 \mathrm{~mm}$.

Conclusions: The difference in MMO between the two genders is statistically significant. At both genders the mouth opening was reduced with age.
\end{abstract}

Keywords: Mouth opening; age; masticatory system; temporomandibular disorders

Received: 03 August 2020; Accepted: 29 November 2020; Published: 30 March 2021.

doi: 10.21037/fomm-20-50

View this article at: http://dx.doi.org/10.21037/fomm-20-50

\section{Introduction}

It is indeed an axioma that we cannot diagnose and furthermore treat a disorder of a system if we aren't able to understand anatomical and physiological interaction between all the component of this system. To evaluate the functionality of the temporomandibular joint (TMJ), patterns of mandibular movements are the best and the simplest indicator that shows whether the correlation between anatomical integrity and functionality requirements are harmonious or not.

Measuring the range of mandibular movements is a technique that allows us to assess and evaluate the functionality of the masticatory system. A variety of instruments have been developed and used to measure the range of mandibular movements, like as a millimeter rule, a millimeter caliper and more sophisticated one, electronic device such as mandibular kinesiograph (MKG) which electronically records mandibular incisor-point movements in three dimensions; measurement of vertical velocity is also provided by differentiating the vertical position signal (1). Different sources have shown that measurements reliability for evaluating the mandibular motion using a millimeter ruler is very good.

The first assessment of masticatory muscle function is with no doubt the performance of the mouth opening movements that reflects the mandibular range of motion in sagittal and vertical plane. The normal range of mouth opening is estimated to be between $53-58 \mathrm{~mm}(2,3)$.

A restricted mandibular motion is considered to be an 
Table 1 Summary of MMO normal range values according to different quoted sources

\begin{tabular}{lll}
\hline Reference & Year & Mouth opening [mean (in mm)] \\
\hline Posselt (7) & 1952 & 43,3 \\
Braus (11) & 1954 & $32-62$ \\
Shore (12) & 1959 & $33-45$ \\
Nevakari (13) & 1960 & Men 57.5; women 54.0 \\
Travell (8) & 1960 & Men 59.0; women 53.0 \\
Posselt (14) & 1962 & $50-60$ \\
Sheppard (15) & 1965 & 46.9 \\
Posselt (16) & 1968 & 43.4 \\
Ingervall (17) & 1970 & 51.3 \\
Ingervall (18) & 1971 & 52 \\
Bosman (19) & 1974 & Men 54.4; women 53.6 \\
Agerberg (2) & 1974 & Men 42-77 (mean 58.6); \\
& & women 39-75 (mean 53.3) \\
Dijkstra (20) & 1999 & $44-70$ (mean 57.2) \\
Zawawi (9) & 2003 & Men 42-68; women 40-57 \\
\hline
\end{tabular}

$\mathrm{MMO}$, maximal mouth opening.

opening movement less than $40 \mathrm{~mm}$ for muscular disorders and less than $35 \mathrm{~mm}$ for joint disorders (4). However, various contributing factors must be considered such as: a-internal factors: patient's age, body size (height), gender, developmental abnormalities, oral neoplastic diseases, trauma, odontogenic infections, and other systemic conditions as Systemic Lupus Erythematosus, Systemic Sclerosis, Rheumatoid Arthritis, and b-external factors: ethnicity, racial features, geographical variations, etc.

Basically, any disorders in TMJs may result in a decrease in its mobility and subsequently in a decrease of mandibular range of motion. Consequently, mouth opening will be reduced, and the opening pattern will be changed. This is the reason that mouth opening is used as an outcome parameter in evaluating the efficacy of therapeutic interventions on TMJ pathology (3).

Mouth opening reflects the mobility of TMJs and at the same time reflects mandibular length (the distance between the mandibular condyle and the lower incisors) (4-6). Previously documented literature has shown maximal mouth opening to have ethnic, racial and gender variations (2,7-10). Previously reported mean of Maximal Mouth Opening (MMO) has been ranged from $43.3 \mathrm{~mm}$ reported by Posselt to $59.0 \mathrm{~mm}$ (for men only), as reported by Travell $(7,8)$. Different authors had reported different mean values of maximum mouth opening, as shown in Table 1.

No previous study has been done to assess the average maximum mouth opening among the Albanians.

The aim of the study was to estimate the average maximum mouth opening in a representative sample of individuals in Albania population.

\section{Methods}

A total of 1,348 adults have participated in the present study during the period of June 2016 to August 2018. Informed consent was obtained from all participating subjects. The participants were 750 men and 598 women, aged 20-78 years old. The participants were patients in the dental Orkidea clinic.

The study was conducted in accordance with the Declaration of Helsinki (as revised in 2013). In Albania, ethical approval is required only in the case of clinical trials. The study was not a clinical trial, but rather collecting anthropometric data. Informed consent was obtained from all participating subjects.

The inclusion/exclusion criteria in this study were the following:

(I) Being of Albanian ancestry for at least 4 generations;

(II) Had signed the consent form;

(III) No history of trauma on jaw, face, head;

(IV) No history of regional disorders of the masticatory system, reducing joint mobility or pain, or restriction in mandible movement;

(V) No history of bruxism;

(VI) No more than two teeth absent (excluding wisdom teeth);

(VII) No dental prosthesis on anterior teeth;

(VIII) Not more than $1 \mathrm{~mm}$ of attrition on the incisal edges;

(IX) No history of orthodontic treatment;

(X) No systemic disease such as Juvenile Rheumatoid Arthritis, Systemic Lupus Erythematosus or Systemic Sclerosis.

TMJ, masticatory muscles: masseter, temporalis, medial and lateral pterygoid muscles were palpated bilaterally to evaluate if this tissue had pain or not. We also had evaluated the presence of joint sounds on motion with a stethoscope.

Clinical examination was performed for every patient by a single examiner (Beraj S). The examination and measurements were performed at a consistent time (from 
Table 2 Demographic features of subjects enrolled in study

\begin{tabular}{|c|c|c|c|}
\hline Variable & Number & Mean value $\pm S D$ & Percentage \\
\hline \multicolumn{4}{|l|}{ Sex } \\
\hline Men & 750 & $49.88 \pm 15.41$ & 55.63 \\
\hline Women & 598 & $50.1 \pm 15.63$ & 44.36 \\
\hline Mean value $\pm S D$ & $49.99 \pm 10.5$ & & \\
\hline \multicolumn{4}{|l|}{ Group-age } \\
\hline 20-30 years & 261 & & \\
\hline Men & 161 & & 11.94 \\
\hline Women & 100 & & 7.41 \\
\hline $31-40$ years & 494 & & \\
\hline Men & 293 & & 21.73 \\
\hline Women & 201 & & 14.91 \\
\hline $41-50$ years & 352 & & \\
\hline Men & 154 & & 11.42 \\
\hline Women & 198 & & 14.68 \\
\hline $51-60$ years & 79 & & \\
\hline Men & 37 & & 2.74 \\
\hline Women & 42 & & 3.11 \\
\hline $61-70$ years & 85 & & \\
\hline Men & 63 & & 4.67 \\
\hline Women & 22 & & 1.63 \\
\hline $71-78$ years & 77 & & \\
\hline Men & 42 & & 3.11 \\
\hline Women & 35 & & 2.59 \\
\hline
\end{tabular}

9 a.m. till 11 a.m.). The subjects were seated comfortably in an upright position on the dental chair, to avoid the possible bias of different head and neck position in our results. Each participant was instructed to accommodate two requests:

(I) Close their teeth in habitual occlusion; With teeth occluded in habitual occlusion and with a non-toxic pencil we marked the reference line of the vertical overlap of maxillary central incisor on the labial surface of central mandibular incisors, measuring in this way the amount of vertical overlap or overbite to open their mouth as wide as possible without any sign of discomfort.

(II) In maximal mouth opening position we measured the MMO. To measure MMO we used a Vernier
Calipers with a $0.05 \mathrm{~mm}$ accuracy to measure the maximal mouth opening. The caliper was place at the mesial incisal edge of the maxillary left central incisor that is the most vertically oriented and measured vertically to the mesial labio-incisal edge of the left mandibular central incisor for the measurements of maximal interincisal distance.

To ensure the accuracy and reproducibility of the outcomes we repeated the measurements three times for each subject within 30 minutes, letting participants to rest for 10 minutes between two consecutive measurements. The mean value of these three measurements were recorded as the result for each participant. The amount of vertical incisor overlap (overbite) was added to the mean value of mouth opening for each participant to calculate the real value of the mouth opening. The age, gender and MMO were recorded for each participant.

\section{Statistical analysis}

MMO was measured in millimeters. Mean MMO values were analyzed according to age ranges and gender which were established appropriately for statistical analysis. Hence, the sample was divided according to group-age and gender: 6 age groups (20-30 years; $31-40$ years; $41-50$ years; 51-60 years; $61-70$ years; $71-78$ years) and 2 gender groups male and female were assigned.

For statistical analysis we used independent t-test to evaluate the differences in MMO relative to sex for different group ages. Person's correlation was used to assess the correlation between MMO and group-ages for each gender. A $P$ value $<0.05$ was the criteria of considering the result statistically significant. Continuous variables are reported as mean \pm standard deviation. The statistical analysis has been performed using open source software $\mathrm{R}$ version 3.0.1 from R Foundation for Statistical Computing, Vienna, Austria.

\section{Results}

The mean age of the 1,348 adults was $49.99 \pm 10.5$ years. The mean age of males was $49.88 \pm 15.41$ years and females slightly larger $50.1 \pm 15.63$ years with no statistical significance (The $t$-value is -0.02206 . The $\mathrm{P}$ value is 0.491417; Table 2).

The average $M M O$ for all participants was $43.1 \pm 2.49 \mathrm{~mm}$. The mean MMO of males $(43.6 \pm 3.63 \mathrm{~mm})$ was statistically larger than the mean of MMO of females $(40.8 \pm 1.38 \mathrm{~mm}$; $t$-value $=2.46845 ; \mathrm{P}=0.016596$ ). 
Table 3 Pearson's correlation test for linear association between each group age and MMO independent for both genders

\begin{tabular}{lccccccc}
\hline Group age & $20-30$ years & $31-40$ years & $41-50$ years & $51-60$ years & $61-70$ years & $71-78$ years & r value \\
\hline Mean Men & $27.3 \pm 3.04$ & $35.2 \pm 3.09$ & $47.1 \pm 3.27$ & $54.2 \pm 3.03$ & $63.1 \pm 3.18$ & $72.3 \pm 3.06$ \\
MMO Men & $44.4 \pm 2.46$ & $46.0 \pm 2.50$ & $45.2 \pm 2.40$ & $42.7 \pm 2.39$ & $41.0 \pm 2.51$ & $42.3 \pm 2.49$ \\
Mean Women & $26.5 \pm 3.09$ & $36.4 \pm 3.12$ & $46.9 \pm 3.46$ & $55.1 \pm 4.01$ & $62.4 \pm 4.21$ & $73.2 \pm 3.08$ \\
MMO Women & $41.6 \pm 2.74$ & $43.0 \pm 2.90$ & $42.9 \pm 2.87$ & $38.2 \pm 2.66$ & $40.1 \pm 2.36$ & $39.0 \pm 2.77$ & -0.6883 \\
\hline
\end{tabular}

$\mathrm{MMO}$, maximal mouth opening.

Table $4 \mathrm{~T}$ test to evaluate the differences in MMO relative to sex for different group ages

\begin{tabular}{lccccccc}
\hline Group age & $20-30$ years & $31-40$ years & $41-50$ years & $51-60$ years & $61-70$ years & $71-78$ years & $P$ value \\
\hline MMO M & $44.4 \pm 2.46$ & $46.0 \pm 2.50$ & $45.2 \pm 2.40$ & $42.7 \pm 2.39$ & $41.0 \pm 2.51$ & $42.3 \pm 2.49$ \\
MMO W & $41.6 \pm 2.74$ & $43.0 \pm 2.90$ & $42.9 \pm 2.87$ & $38.2 \pm 2.66$ & $40.1 \pm 2.36$ & $39.0 \pm 2.77$ & 0.009827 \\
\hline
\end{tabular}

$\mathrm{MMO}$, maximal mouth opening.

There was a moderate negative correlation between $\mathrm{MMO}$ and group ages for both male and female subjects (Pearson's correlation coefficient respectively $\mathrm{r}=-0.7756$; $\mathrm{r}=-0.6883)$.

The correlation between MMO and the group ages was also significant when data for male and female subjects were analyzed independently $(\mathrm{P}=0.009827)$. However, this correlation was slightly stronger for male subjects $(\mathrm{r}=-0.7756$; Tables 3,4).

\section{Discussion}

It is widely accepted that MMO represents an individual feature determined by interaction of a variety of factors (internal and external), however there are a lot of studies that have attempted to gather an average range of MMO in different ethnic groups. This study provides the normal average value of $\mathrm{MMO}$ for different group ages and gender in Albanian population for the first time. The MMO of healthy adult Albanian population was $43.1 \pm 2.49 \mathrm{~mm}$ (43.6 \pm 3.63 and $40.8 \pm 1.38 \mathrm{~mm}$ for males and females respectively). This result of course has some differences with the results of previous study in literature. This difference may be explained due to the fact that Albanian ethnicity has different facial proportion and different body size compared with the other ethnicities. It has been showed that exists a positive correlation between race and MMO (21). Another important factor that can lead to the variation of reported MMO is the methodology used in different studies to evaluate the MMO. MMO can be evaluated as the sum of interincisal distance and overbite, or as simple interincisal distance. Despite the fact that interincisal distance is considered the functional opening capacity of the mouth, we recognize that the real value of functional opening capacity of the mouth should be calculated as the sum of interincisal distance plus overbite $(11,12,20,22)$.

MMO of male subjects in our study is statistically significantly greater than that of female subjects $(\mathrm{P}=0.009827)$, and this trend was persistent over the all group ages. The same tendency is referred from Travell, Nevakari, Bosman, and Yao $(8,13,19,23)$.

This difference between genders could be explained by the fact that males and females have different facial proportion (14-16). Ingervall et al. have shown that mouth opening was correlated with measurements of the cranial base and the mandible; Skomina et al. have shown that mouth is on average $2 \mathrm{~mm}$ wider in male compared with female $(17,18,22)$.

Age is an important factor influencing the MMO. At both genders the mouth opening was reduced with age. We found that MMO increase from young adulthood into mature adulthood (from 20-30 years group - age to 31-40 years group - age) and then gradually decrease as aging progresses. In fact, there was a moderate negative statistically significant correlation between MMO and group ages for both male and female subjects, which means that as aging progresses the MMO decrease (Pearson's correlation coefficient for male and female respectively $\mathrm{r}=-0.7756 ; \mathrm{r}=-0.6883)$.

These findings are consistent with the results of other 
authors, such as quoted from Ying QV, Yao KT, and Juan FC $(21,23,24)$. This trend may be explained by normal anatomic development of the TMJ and physiological adaptation related to bruxism and trauma.

With the increase of the age the number of subjects enrolled in study is decreased. This fact may be as consequence of our inclusion criteria's: no more than two teeth absent (excluding wisdom teeth); no dental prosthesis on anterior teeth; not more than $1 \mathrm{~mm}$ of attrition on the incisal edges.

This study has two limitations. First limitation is the fact that we may have include in our study the asymptomatic subjects that have limited range of mandibular motion, since the diagnostic imaging of the TMJ were not enclosed in our inclusion criteria's. This fact can bias to some extent our results.

Second limitation is the fact that the subjects of this study were enrolled from a group of patients who were undergoing regular dental examination in our dental clinic, which means that they may not be representative of the whole Albanian population.

The present study attempts to assess the mouth opening for the Albanian population. These data are important because this is the first study of MMO conducted in Albania. Despite the limitation of this study, we can conclude that the MMO in a group of Albanian population is $43.1 \mathrm{~mm}$. Both age and gender have significant influences on the MMO of the healthy Albanian population. Measuring the MMO is a simple and quick test which may be performed by any dentist, within any clinical settings. The result of this test can help the dentist to refer the patient on the specialist. We believe that these data will be of great importance for future studies as well as clinical assessment of Albanian population addressing the masticatory system. Future other investigations must be conducted to examine an increased sample size from a multicenter setting. Other contributing factors such as the impact of body weight and height; the length, wide and mandibular angle; as well as other underlying factors such as the profession and habits should be recorded to assess their impact on the MMO, furthermore the results should be compared between normal individuals and those diagnosed with temporomandibular disorders.

\section{Acknowledgments}

Funding: None.

\section{Footnote}

Data Sharing Statement: Available at https://fomm. amegroups.com/article/view/10.21037/fomm-20-50/dss

Peer Review File: Available at https://fomm.amegroups.com/ article/view/10.21037/fomm-20-50/prf

Conflicts of Interest: Both authors have completed the ICMJE uniform disclosure form (available at https://fomm. amegroups.com/article/view/10.21037/fomm-20-50/coif). The authors have no conflicts of interest to declare.

Ethical Statement: The authors are accountable for all aspects of the work in ensuring that questions related to the accuracy or integrity of any part of the work are appropriately investigated and resolved. The study was conducted in accordance with the Declaration of Helsinki (as revised in 2013). In Albania, ethical approval is required only in the case of clinical trials. The study was not a clinical trial, but rather collecting anthropometric data. Informed consent was obtained from all participating subjects.

Open Access Statement: This is an Open Access article distributed in accordance with the Creative Commons Attribution-NonCommercial-NoDerivs 4.0 International License (CC BY-NC-ND 4.0), which permits the noncommercial replication and distribution of the article with the strict proviso that no changes or edits are made and the original work is properly cited (including links to both the formal publication through the relevant DOI and the license). See: https://creativecommons.org/licenses/by-nc-nd/4.0/.

\section{References}

1. Jankelson B. Measurement accuracy of the mandibular kinesiograph - a computerized study. J Prosthet Dent. 1980;44:656-66.

2. Agerberg G. Maximal mandibular movements in young men and women. Sven Tandlak Tidskr 1974;67:81-100.

3. Svechtarov V, Hristova M, Nencheva-Sveshtarova $\mathrm{S}$, . Mandibular range of motion and its relation to temporomandibular disorders. Scripta Scientifica Medicinae Dentalis 2015;1:21-6.

4. Li XY, Jia C, Zhang ZC. The normal range of maximum mouth opening and its correlation with height or weight in the young adult Chinese population. J Dent Sci 2017;12:56-9. 
5. Stegenga B, de Bont LG, Dijkstra PU, et al. Short-term outcome of arthroscopic surgery of temporomandibular joint osteoarthrosis and internal derangement: a randomized controlled clinical trial. Br J Oral Maxillofac Surg 1993;31:3-14.

6. Wright V, Hopkins R. The temporo-mandibular joint. Clin Rheum Dis 1982;8:715-22.

7. Posselt U. Studies in mobility of the human mandible. Acta Odontol Scand 1952;10:1-60.

8. Travell J. Temporomandibular joint pain referred from muscles of the head and neck. J Prosthet Dent. 1960; 10:745-63.

9. Zawawi KH, Al-Badawi EA, Lobo SL, et al. An index for the measurement of normal maximum mouth opening. $\mathrm{J}$ Can Dent Assoc 2003;69:737-41.

10. Dijkstra PU, Kropmans TJ, Stegenga B, et al. Ratio between vertical and horizontal mandibular range of motion. J Oral Rehabil. 1998;25:353-7.

11. Braus H. Bewegungsapparat. 3rd ed. Berlin: Auflage; 1954.

12. Shore NA. Occlusal equilibration and temporomandibular joint dysfunction. Lippincott; 1959.

13. Nevakari K. "Elapsio Praearticularis" of the Temporomandibular Joint a Pantomographic Study of the So-Called Physiological Subluxation. Acta Odontol Scand 1960;18:123-70.

14. Posselt U. Physiology of occlusion and rehabilitation. Blackwell scientific publications, 1962:31-9.

15. Sheppard IM. Maximal incisal opening. A diagnostic

doi: $10.21037 /$ fomm-20-50

Cite this article as: Beraj S, Vyshka G. The normal range of mouth opening in a group of Albanian population. Front Oral Maxillofac Med 2021;3:1. index? J Dent Med 1965;20:13-5

16. Posselt U. Physiology of occlusion and rehabilitation. Blackwell Scientific; 1968.

17. Ingervall B. Range of movement of mandible in children. Scand J Dent Res 1970;78:311-22.

18. Ingervall B. Variation of the range of movement of the mandible in relation to facial morphology in young adults. Scand J Dent Res 1971;79:133-40.

19. Bosman AE. Hinge axis determination of the mandible: an investigation of the accuracy of mandibular hinge axis determination by the kinematic method as compared with substitutive approximations. Leiden: Stafleu en Tholen; 1974.

20. Dijkstra PU, Hof AL, Stegenga B, De Bont LG. Influence of mandibular length on mouth opening. J Oral Rehabil 1999;26:117-22.

21. Ying QV, Bacic J, Abramowicz S, et al. Cross sectional: normal maximal incisal opening and associations with physical variables in children. Pediatr Dent 2013;35:61-6.

22. Skomina Z, Verdenik M, Hren NI. Effect of aging and body characteristics on facial sexual dimorphism in the Caucasian Population. Plos One 2020;15:e0231983.

23. Yao KT, Lin CC, Hung CH. Maximum mouth opening of ethnic Chinese in Taiwan. J Dent Sci 2009;4:40-4.

24. Juan FC, Carlo EM, Alejandro JC, et al. Clinical characterization of mouth opening among Mexican adolescents and young adults. J Dent Sci 2012;7:81-4. 